\title{
POLITICAS ECONÓMICAS PARA SUPERAR LA CRISIS TURÍSTICA DE LA COVID-19
}

\section{ECONOMIC POLICIES TO OVERCOME THE COVID-19 TOURISM CRISIS}

Beatriz Benítez-Aurioles (Universidad de Málaga)*

\section{Resumen}

La gravedad y persistencia de la crisis turística asociada a la COVID-19 ha impulsado a los gobiernos a prestar especial atención al turismo en el diseño de la política económica. En este sentido, el propósito básico de este artículo es identificar las características de los programas implementados para la reactivación del turismo y, más concretamente, sus objetivos, sus instrumentos y sus principales destinatarios. El marco metodológico utilizado es el que proporciona el análisis económico convencional, lo cual se justifica, entre otras razones, por el énfasis que las autoridades públicas han puesto en la recuperación de la actividad económica relacionada con el turismo. Pues bien, el análisis de las medidas implementadas confirma el protagonismo de los instrumentos fiscales y financieros destinados a apoyar a las empresas y, particularmente, a las PYMES. También son destacables las acciones dirigidas a mantener el empleo y la renta de los trabajadores. En cualquier caso, si bien este tipo de actuaciones puede contribuir a amortiguar el impacto de la crisis, también existe el riesgo de que una parte de las ayudas la reciban empresas que están condenadas a abandonar el mercado con lo que se comprometería la rentabilidad social de los recursos públicos. Tras la pandemia, parece que el protagonismo habría de trasladarse a otras políticas como las de promoción, donde la coordinación entre los distintos niveles de las administraciones públicas, la colaboración público-privada y el concurso de los medios de comunicación son herramientas fundamentales para recuperar la confianza de los turistas.

Palabras clave: COVID-19, crisis, turismo, política económica.

Códigos JEL: H12, L83

\begin{abstract}
The severity and persistence of the tourism crisis associated with COVID-19 has prompted governments to pay special attention to tourism in the design of economic policy. In this sense, the basic purpose of this article is to identify the characteristics of the programs implemented for the reactivation of tourism and, more specifically, their objectives, their instruments and their main recipients. The methodological framework used is the one provided by conventional economic analysis, which is justified, among other reasons, by the emphasis of public authorities on the recovery of economic activity related to tourism. Thus, the analysis of the implemented measures confirms the prominence of fiscal and financial instruments intended to support companies and, particularly, SMEs. The actions aimed at maintaining the employment and income of workers are also noteworthy. In any case, although this type of action can help cushion the impact of the crisis, there is also the risk that a part of the aid will be received by companies that are doomed to leave the market, hence compromising the social profitability of
\end{abstract}

\footnotetext{
*Correo-e: bbaurioles@gmail.com, https://orcid.org/0000-0002-4224-9184

Fecha de envío: 09/08/2021. Fecha de aceptación: 16/01/2022.
} 
public resources. After the pandemic, it seems that the leading role would have to shift to other policies such as promotion policies, where coordination between the different levels of public administrations, public-private collaboration and the participation of the media are fundamental tools to recover the confidence of tourists.

Keywords: COVID-19, crisis, tourism, economic policy.

JEL Codes: H12, L83

\section{INTRODUCCIÓN}

El aumento de la percepción del riesgo por parte de los turistas ha dado lugar a crisis, relativamente frecuentes, que han afectado a destinos concretos (Benítez-Aurioles, 2019). En estos casos, los ataques terroristas (Corbet et al., 2019), la incertidumbre política (TomczewskaPopowycz y Quirini-Popławski, 2021) o los desastres naturales (Rosselló et al., 2020) disminuyeron los flujos turísticos hacia determinados lugares. También existen acontecimientos que han contraído la demanda turística a nivel global. Por ejemplo, en este siglo, los ataques terroristas del 11 de septiembre de 2001 (Blake y Sinclair, 2003), la crisis sanitaria que causó el brote del virus del síndrome respiratorio agudo grave (SARS) en 2003 (McKercher y Chon, 2004), o la Gran Recesión de 2007 (Pechlaner y Frehse, 2010) redujeron la llegada de turistas internacionales en el mundo.

No obstante, la crisis sanitaria, social y económica que se desencadenó a principios de 2020, como consecuencia de la pandemia asociada a la COVID-19, afectó de manera particularmente intensa al turismo, alcanzando unas dimensiones desconocidas. Toda la cadena de valor relacionada con el turismo, a nivel global, sufrió un impacto mayúsculo. Muchas empresas se vieron forzadas a suspender su actividad o, incluso, a abandonar definitivamente el mercado debido al hundimiento de la demanda o de las restricciones legales establecidas para tratar de contener la expansión del virus. Esta situación supuso un reto para las autoridades públicas que se vieron obligadas a reorientar sus estrategias para amortiguar los efectos de la pandemia. Sobre esa base, parece pertinente un análisis que responda, al menos, a las siguientes preguntas: ¿Qué características tienen los programas implementados para la recuperación del turismo? Y, más concretamente, ¿Qué instrumentos se han utilizado? ¿Cuáles son sus objetivos concretos? ¿Quiénes son sus destinatarios inmediatos? Para ello, en el siguiente apartado se realizará un repaso de las principales aportaciones académicas que han analizado las acciones públicas orientadas a superar las crisis turísticas. A continuación, se presentará el marco metodológico. Más adelante, se exponen los rasgos principales de la crisis turística que han justificado las acciones públicas. Después se analizarán las respuestas de política económica, prestando especial atención al caso de España. Terminaremos con las conclusiones.

\section{REPASO DE LA LITERATURA}

Las aportaciones académicas sobre las acciones públicas para enfrentar las crisis turísticas están, hasta cierto punto, fragmentadas en la medida en que se refieren a análisis concretos de casos o destinos particulares. En principio, podrían agruparse en tres grandes categorías según el tipo de intervención realizada (Ritchie y Jiang, 2019): infraestructuras; apoyo financiero a empresas; y campañas de promoción turística. Aunque, con cierta frecuencia, los análisis han abordado más de una categoría, la división es útil a efectos expositivos ya que, además, dependiendo de la naturaleza de la crisis turística que se pretendía enfrentar, la política económica articulada por los gobiernos puso el énfasis en unas medidas u otras. La revisión bibliográfica se ha realizado sobre la base de las investigaciones publicadas en las dos últimas décadas que, de hecho, concentran la práctica totalidad de los artículos publicados relacionados con las crisis 
turísticas. De hecho, una búsqueda conjunta de los términos tourism, crisis, y policies en la base de datos Web of Science demuestra que más del $95 \%$ de los artículos se publicaron a partir del año 2000.

\subsection{Infraestructuras}

Los terremotos, tsunamis, inundaciones, etc. pueden afectar a aeropuertos, carreteras o redes de electricidad y telecomunicaciones hasta el punto que impidan la llegada de turistas (Rosselló et al., 2020). Además, este tipo de sucesos también suelen dañar la capacidad de alojamiento y a los atractivos turísticos de la zona. En ocasiones la recuperación puede ser larga y, mientras tanto, las autoridades pueden optar por establecer campañas que promocionen otros destinos turísticos (Orchiston y Higham, 2016). No obstante, aunque las estrategias de recuperación tienen múltiples dimensiones, incluidas las que afectan al capital social (Guo et al., 2018), la prioridad suele ser la restauración de las infraestructuras previas al desastre.

Es lógico que, dada la estrecha conexión con el desarrollo turístico (Mandić et al., 2018) y la función que desempeñan para facilitar el acceso a determinadas zonas (Sharpley y Craven, 2001) se haya prestado una especial atención a la infraestructura necesaria para facilitar la llegada de turistas (Casado, 1998). En este sentido, se han realizado diferentes análisis de casos concretos que ilustran las actuaciones de las autoridades públicas para recuperar las infraestructuras (Chan et al., 2020; Robinson y Jarvie, 2008; Schmude et al., 2018). Una vez restaurada las infraestructuras y las instalaciones turísticas básicas, empiezan a cobrar protagonismo las campañas de marketing y publicidad en una etapa posterior al desastre (Beirman, 2003).

No obstante, aunque es evidente que el buen funcionamiento de las infraestructuras es un elemento clave del desarrollo turístico (Sheller, 2021) y que las experiencias de las campañas de marketing que refuerzan la seguridad del destino después de un desastre natural (Yang et al., 2011) pueden ser útiles para enfrentar la crisis turística de la COVID-19, parece que el énfasis, al menos a corto plazo, está en otra categoría de intervenciones.

\subsection{Apoyo financiero a empresas}

En segundo lugar, nos encontramos el apoyo financiero a las empresas turísticas afectadas por la crisis a través de exenciones o aplazamientos de impuestos, garantías para préstamos o con reducciones de tipos de interés, y subvenciones directas, entre otras medidas (Ritchie y Jiang, 2019). Este tipo de acciones se han ensayado en anteriores crisis turísticas y forma parte de los programas convencionales de política económica orientados al mantenimiento de la actividad productiva. Por ejemplo, el brote de fiebre aftosa que afectó al ganado del Reino Unido en 2001 tuvo un impacto negativo, no solo en las explotaciones agrícolas, sino en las empresas de turismo rural que vieron disminuida drásticamente su actividad por las restricciones en el acceso a determinadas áreas (Thompson et al., 2002). La respuesta del gobierno británico fue la implementación de compensaciones, tanto a las explotaciones agrícolas como a las empresas turísticas, aunque, según algunos análisis, las primeras tuvieron un trato preferente que no se correspondía con su aportación relativa a la economía del conjunto del país (Sharpley y Craven, 2001). A propósito de esta experiencia surgen, al menos, dos reflexiones que, quizás, pueden ser útiles para la gestión de la crisis de la COVID-19. La primera está relacionada con la competencia que puede aparecer entre sectores por la captación de ayudas públicas, que corren el riesgo de ser distribuidas en función de la presión de los lobbys y no de lo que exigiría la búsqueda de la rentabilidad social en la asignación de los fondos públicos. La segunda se refiere a la posibilidad de que el apoyo financiero a las empresas tenga un sesgo cortoplacista y, en consecuencia, no se utilice para mantener empresas cuya viabilidad a largo plazo no está garantizada. 
Otro análisis que puede aportar alguna enseñanza sobre los efectos del apoyo a las empresas turísticas ante las crisis del sector es el realizado por Blake y Sinclair (2003) sobre la respuesta de las autoridades estadounidenses ante la crisis surgida a raíz de los atentados terroristas del 11 de septiembre de 2001. Estos autores utilizan un modelo de equilibrio general computable para valorar distintas acciones públicas. Los resultados demostraron que las políticas implementadas disminuyeron los costes de ajustes de las empresas amortiguando la caída de la producción y el empleo. Por otro lado, confirmaron la eficacia de los subsidios a la producción y las reducciones de impuestos dirigidos a los subsectores más afectados por la crisis frente a otras medidas como las subvenciones a los gastos turísticos. No obstante, conviene advertir que estas conclusiones deben enmarcarse en el contexto de una crisis que afectó en mayor medida a las compañías aéreas que a los establecimientos de alojamiento turístico.

También resulta particularmente interesante el análisis de Wu y Wall (2006) sobre la política adoptada por el gobierno chino ante la crisis turística asociada al SARS de 2003. La conclusión fue que las acciones púbicas contribuyeron a la rápida recuperación del mercado turístico. En particular, más que las exenciones de impuestos u otras deducciones a las empresas, fueron más efectivas las campañas de promoción puestas en marcha por las oficinas regionales de turismo.

Huang y Min (2002), por su parte, aportaron evidencia sobre la recuperación del mercado turístico de Taiwan tras el terremoto ocurrido el 21 de septiembre de 1999. En la misma línea que los estudios anteriores se concluyó que las medidas adoptadas por el gobierno, sobre todo en el ámbito de la promoción, aunque también con préstamos a la industria turística, contribuyeron a amortiguar los efectos que tuvo el terremoto sobre el mercado turístico.

\subsection{Campañas de promoción}

En los apartados anteriores se ha hecho referencia a la importancia de las campañas de promoción como estrategia para superar las crisis turísticas. En ocasiones, los medios de comunicación pueden transmitir una imagen distorsionada de la realidad que agrava los problemas. Por ejemplo, Murphy y Bayley (1989) observaron que, tras la erupción del monte Santa Helena de 1980 en Washington (Estados Unidos) y los incendios forestales en East Kootenay de 1985 en la provincia canadiense de Columbia Británica, la prensa sensacionalista no informó adecuadamente sobre la dimensión y las consecuencias reales de los desastres. De acuerdo con estos autores, ambas experiencias demostrarían la necesidad de una cobertura de los acontecimientos equilibrada que podría canalizarse a través de una agencia gubernamental. Al margen de la discusión que puede generar esta propuesta, parece evidente que la colaboración entre las autoridades públicas y los medios de comunicación es una pieza fundamental que puede ayudar a superar las crisis turísticas. En efecto, los medios de comunicación también pueden contribuir a amortiguar los efectos de las crisis por diferentes vías. Por ejemplo, Ciocco y Michael (2007) expusieron que la aceleración de la entrega de fondos públicos para la recuperación de las infraestructuras turísticas, afectadas por los incendios forestales de 2003 al noreste de Victoria (Australia), estuvo impulsado por los medios de comunicación que, tras una cobertura inicialmente sensacionalista del suceso, pusieron de manifiesto la importancia de la pronta recuperación del turismo. Por su parte, Chacko y Marcell (2008) argumentaron sobre la importancia de difundir noticias positivas que mejoren la imagen del destino, tomando como referencia la devastación causada por el huracán Katrina en 2005 en Nueva Orleans. En una línea similar, otros autores han destacado el papel de los medios de comunicación para generar confianza en el turista (Tsai y Chen, 2010).

La importancia de transmitir una información fiable también quedó acreditada cuando los viajes con origen y destino en los países asiáticos se recuperaron rápidamente al demostrarse que eran seguros y que la crisis del SARS de 2003 se había superado (Cooper, 2006). En realidad, la literatura que relaciona el riesgo con la demanda turística es muy abundante (Holm 
et al., 2017; Yang y Nair, 2014) y refuerza la idea de que la seguridad es una variable básica que afecta directamente a los flujos turísticos.

En el contexto anterior, las campañas de promoción turística son un pilar esencial en el diseño de una política económica para la recuperación del mercado turístico (Mair et al., 2016). También en este caso la experiencia en la gestión de las crisis anteriores puede dar algunas pistas para enfrentar la crisis de la COVID-19. Así, por ejemplo, Carlsen y Hughes (2008) analizaron el mercado turístico en las Maldivas después del tsunami de 2004 y sugirieron la conveniencia de diferenciar las estrategias de marketing según las características de los mercados emisores, demostrando la eficacia de las medidas orientadas a recuperar la confianza en el destino.

Otra dimensión de la intervención pública está en el fomento de acuerdos de cooperación con organizaciones turísticas relevantes que tengan potencial influencia en la demanda turística. En cualquier caso, al margen de las iniciativas privadas, el protagonismo de las "partes interesadas" (stakeholders) públicas es muy relevante (Presenza y Cipollina, 2010).

\section{MARCO METODOLÓGICO}

A pesar de los esfuerzos realizados por los investigadores sigue sin haber un consenso en torno a la definición de turismo (Netto, 2009). No obstante, de la definición que proporciona la Organización Mundial del Turismo se desprende la posibilidad de una aproximación multidisciplinar: "El turismo es un fenómeno social, cultural y económico que supone el desplazamiento de personas a países o lugares fuera de su entorno habitual por motivos personales, profesionales o de negocios" (UNWTO, 2021a). La referencia a lo social, cultural y económico sugiere distintos enfoques metodológicos para su estudio. De hecho, hace cuarenta años Jafari y Ritchie (1981) identificaron 16 disciplinas diferentes desde las cuales los investigadores podrían abordar el estudio del turismo. Pues bien, la primera disciplina que mencionan es la Economía y, en este sentido, afirmaron que persistían en torno a esta aproximación algunas cuestiones: ¿Debería estudiarse el turismo en el contexto de la Economía? ¿Qué contribuciones puede hacer la Economía al estudio del turismo? ¿Hasta qué punto la formación en turismo debería abordar el concepto económico? ¿Qué conceptos y metodologías, en particular, pueden responder mejor a algunas de las necesidades presentes y futuras del estudio del turismo? Actualmente, en cambio, tiene muy poco sentido plantear esas cuestiones porque la importancia económica de la actividad turística es evidente $\mathrm{y}$, por tanto, resulta obvia la pertinencia de un enfoque económico. En consecuencia, el marco teórico que utilizaremos como referencia es el que proporciona el análisis económico basado en el supuesto de que los agentes responden a los incentivos maximizando sus funciones de utilidad y de beneficio. Este enfoque se justifica ante los costes que, en términos de producción y empleo, ha causado la crisis turística relacionada con la COVID-19 y la consiguiente implementación por parte de los gobiernos de políticas que tienen como objetivo básico la recuperación económica, en general, y de las actividades relacionadas con el turismo, en particular.

Un hecho adicional que refuerza la oportunidad de aplicar un marco metodológico apoyado en la Economía lo encontramos en que los gobiernos han dado preferencia a las contribuciones económicas del turismo (Joppe, 2018). Más concretamente, la profundidad de la crisis turística provocada por la pandemia ha dado prioridad a la recuperación económica de la actividad turística, pasando a un segundo plano otro tipo de consideraciones.

Lo que proponemos, por tanto, es una investigación de economía aplicada en el ámbito de la política económica entendida como la actividad que ejercen los gobiernos para conseguir sus objetivos económicos (Cuadrado, 2019). En este sentido, los argumentos que se utilizan para la intervención pública se basan, en términos genéricos, en los resultados insatisfactorios que alcanzan los mercados respecto a la asignación de recursos, la distribución de la renta y 
de la riqueza, y la estabilización económica (Bénassy-Quéré et al., 2021). En consecuencia, surge la necesidad de justificar la existencia de un problema que reclama la actuación pública. En nuestro caso, cuantificaremos, en primer lugar, los efectos que ha provocado la crisis de la COVID-19 sobre la actividad turística. Para ello, utilizaremos un análisis descriptivo de las variables básicas que han caracterizado la evolución reciente del turismo a nivel internacional, a través de fuentes estadísticas secundarias, para verificar el impacto de la pandemia. Aquí planteamos la hipótesis de que las caídas de la producción están correlacionadas con el peso que, en cada economía, tiene el turismo. Es decir, que en los países en donde el porcentaje que representa el turismo sobre el PIB es mayor la crisis económica ha sido más profunda. O dicho en otros términos, los países más dependientes del turismo son los que han demostrado mayor vulnerabilidad a la recesión económica.

Una vez identificado y cuantificado el problema el siguiente paso será el análisis de las medidas implementadas por los gobiernos de acuerdo con la recopilación que ha realizado la Organización Mundial del Turismo a partir de los datos facilitados por 220 países y territorios y por más de 30 instituciones internacionales y regionales (UNWTO, 2021b). En este contexto, no se tratará de verificar que los países con sectores turísticos más importantes adoptaron paquetes de estímulos económicos, igualmente, más importantes, ya que supondría insistir sobre evidencias que ya han sido documentados (Khalid et al., 2021). Sino, más bien, en conocer, en línea con las preguntas de investigación planteadas en la introducción, qué instrumentos se han utilizado, con qué objetivos y quiénes han sido sus destinatarios. Para ello, nos basaremos en el análisis de contenido de los programas puesto en marcha por los distintos gobiernos. Esta técnica que, por otro lado, posee una larga tradición en las ciencias sociales (Drisko \& Maschi, 2016), nos permitirá, de entrada, una taxonomía de las medidas adoptadas y, sobre esa base, detectar cuáles han alcanzado mayor protagonismo. Así, de entrada, de acuerdo con la experiencia previa, la hipótesis es que se ha producido un sesgo a favor de los instrumentos fiscales y financieros destinados a facilitar la liquidez de las empresas.

En el contexto anterior, se utilizará el caso de España para tratar de confirmar los principales hallazgos de nuestra investigación analizando en detalle el Plan de impulso para el sector turístico: hacia un turismo seguro y sostenible (Gobierno de España, 2020). Adicionalmente, se aportarán algunos indicios, basados en la evolución de las pernoctaciones y del personal empleado en los hoteles, sobre la eficacia de las medidas adoptadas. No obstante, insistimos en que una evaluación rigurosa de las políticas públicas exigiría una serie de datos de los que no disponemos, entre otras razones, porque aún no se han completado los programas anunciados. De hecho, incluso para las políticas ejecutadas no existe información suficiente que satisfagan las necesidades de evaluación con lo que, al menos para España, muchas de las medidas de política económicas no son evaluadas $\mathrm{y}$, por tanto, se siguen diseñando y ejecutando sin la información suficiente para garantizar su eficacia (Jimeno, 2021). Por tanto, el ejercicio que se realiza también pondrá de manifiesto la conveniencia de disponer de una información que permita una evaluación rigurosa de las medidas adoptadas.

\section{EL PROBLEMA: LA CRISIS TURÍSTICA PROVOCADA POR LA PANDEMIA}

Las medidas que tomaron los gobiernos para tratar de contener la expansión de la COVID-19 provocaron, entre otras consecuencias, que 2020 fuera el peor año registrado en la historia del turismo (UNWTO, 2021c). Los confinamientos, las restricciones a la movilidad, el cierre de fronteras, y la suspensión de las actividades productivas no esenciales tuvieron un enorme impacto en toda la cadena de valor turística. Así, por ejemplo, la llegada de turistas internacionales a nivel mundial se desplomó en 2020 respecto a lo ocurrido en 2019, tal como refleja la Figura 1. 


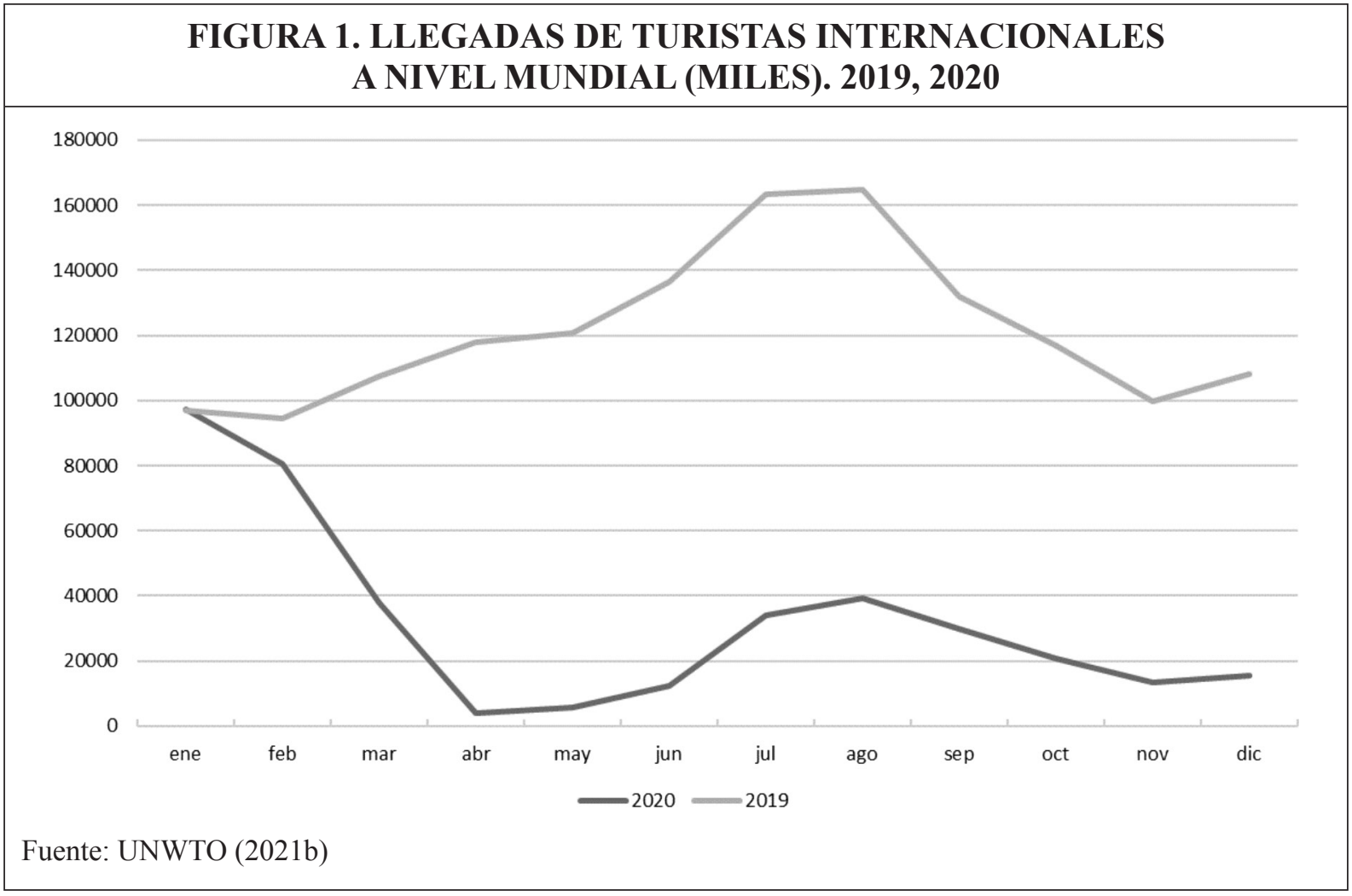

Lógicamente, la vulnerabilidad económica de cada país ante la pandemia depende, en gran medida, del peso que tiene la actividad turística en el conjunto de la economía. En este sentido, en la Figura 2 se relaciona, para el conjunto de países de la OCDE de los que se dispone de información, el porcentaje que representa el turismo sobre el PIB con el porcentaje de variación anual del PIB en 2020. Pues bien, se aprecia una clara relación inversa entre las dos variables. Es decir, las mayores caídas del PIB se produjeron, precisamente, en aquellos países en los que el peso del turismo era más elevado. El caso de España es muy significativo: tiene la mayor participación del turismo en el PIB (12 por cien) de los países considerados y, asimismo, registró la mayor caída de la producción en 2020 (-8,7 por cien).

La crisis turística causada por la COVID-19 no tiene parangón. En primer lugar, su profundidad es absolutamente extraordinaria. En la Figura 3 se observa cómo las dos primeras crisis turísticas del siglo XX provocaron ligeros descensos en la llegada de turistas internacionales en el mundo: en 2001 se registró un descenso del 0,1 por cien y en 2003 del 0,3 por cien. Algo más importante fue el impacto de la gran recesión con una caída del 4 por cien. Sin embargo, en 2020 el descenso fue de un 72,9 por cien lo que supuso retroceder hasta niveles previos a la década de los noventa del siglo pasado. Es decir, el turismo internacional volvió a los registros de hace 30 años (UNWTO, 2021c).

Otro hecho diferenciador respecto a las crisis anteriores lo encontramos en el ritmo de la recuperación. Tradicionalmente, el sector turístico se ha caracterizado por su rápida resiliencia (Benítez-Aurioles, 2020). Así, la llegada de turistas internacionales empezó a experimentar tasas de crecimientos positivas a los 6 meses de los atentados del 11 septiembre de 2001, a los 5 meses desde que en marzo de 2003 la Organización Mundial de la Salud (OMS) emitió una alerta global de la epidemia de SARS, y a los 10 meses desde que en enero de 2009 se hizo evidente el retroceso de la demanda turística debido a la gran recesión (UNWTO, 2021c). Sin embargo, la crisis turística asociada al COVID-19 está siendo más persistente. De hecho, en 


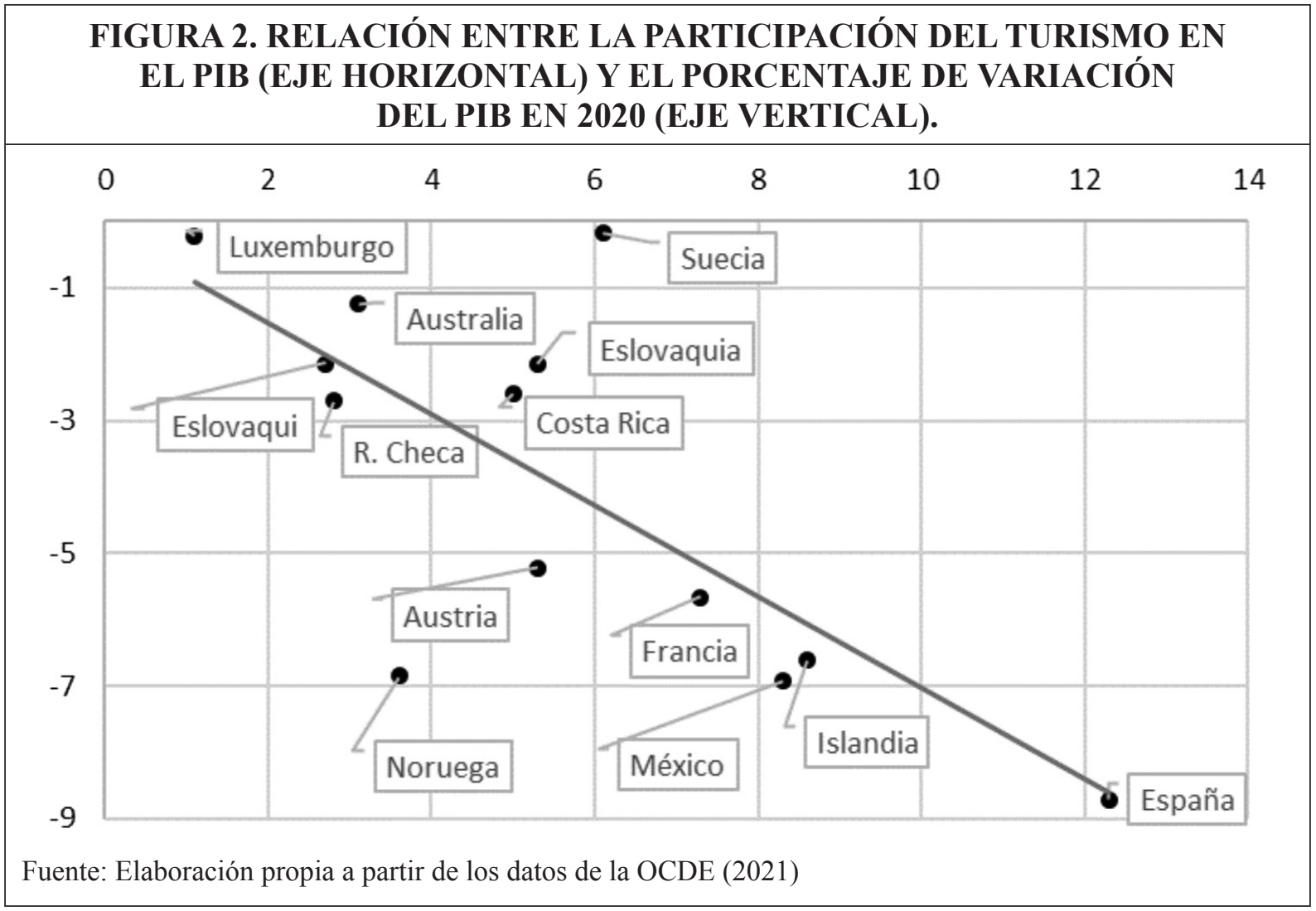

torno al 70 por cien de los expertos consultados por la Organización Mundial del Turismo no prevé que el turismo internacional recupere los niveles pre-pandemia antes de 2023 (UNWTO, 2021d).

La intensidad y persistencia de la crisis turística de la COVID-19, en comparación con las anteriores, se explica, básicamente, por las acciones públicas puestas en marcha para tratar de contener la expansión de la pandemia. Las crisis turísticas previas redujeron la demanda ante el incremento del riesgo percibido por viajar. Sin embargo, la contracción del mercado turístico durante 2020 fue debido a medidas articuladas desde el ámbito público. Por un lado, pocas semanas después de que el 11 de marzo de 2020 la OMS declaró la pandemia, prácticamente todos los destinos mundiales habían introducido restricciones a la movilidad. Es obvio que sin movilidad difícilmente puede haber demanda turística. Pero, además, por el lado de la oferta, muchos países decretaron la suspensión de la actividad productiva no esencial. Por ejemplo, el Real Decreto 10/2020, de 29 de marzo, supuso en España el cierre de los establecimientos hoteleros hasta que, a partir de mayo de ese mismo año se comenzaron a flexibilizar determinadas restricciones. En definitiva, fueron shocks inducidos por los gobiernos los que contrajeron el mercado turístico al reducir, de manera radical, tanto la oferta como la demanda.

En el contexto anterior, los gobiernos han prestado especial atención al sector turístico en el diseño de la política económica para la recuperación en función de su importancia relativa en sus respectivas economías. Por ejemplo, Khalid et al. (2021), basándose en datos de 136 países, encontraron una relación directa entre el tamaño del estímulo económico y la contribución del sector turístico al PIB. Estos hallazgos sugieren que los países con sectores turísticos más grandes adoptaron paquetes de estímulo económico más agresivos para mitigar el impacto de la pandemia.

Los efectos concretos de las políticas económicas implementadas para superar la crisis turística de la COVID-19 dependerán de factores políticos, sociales, culturales, geográficos e 


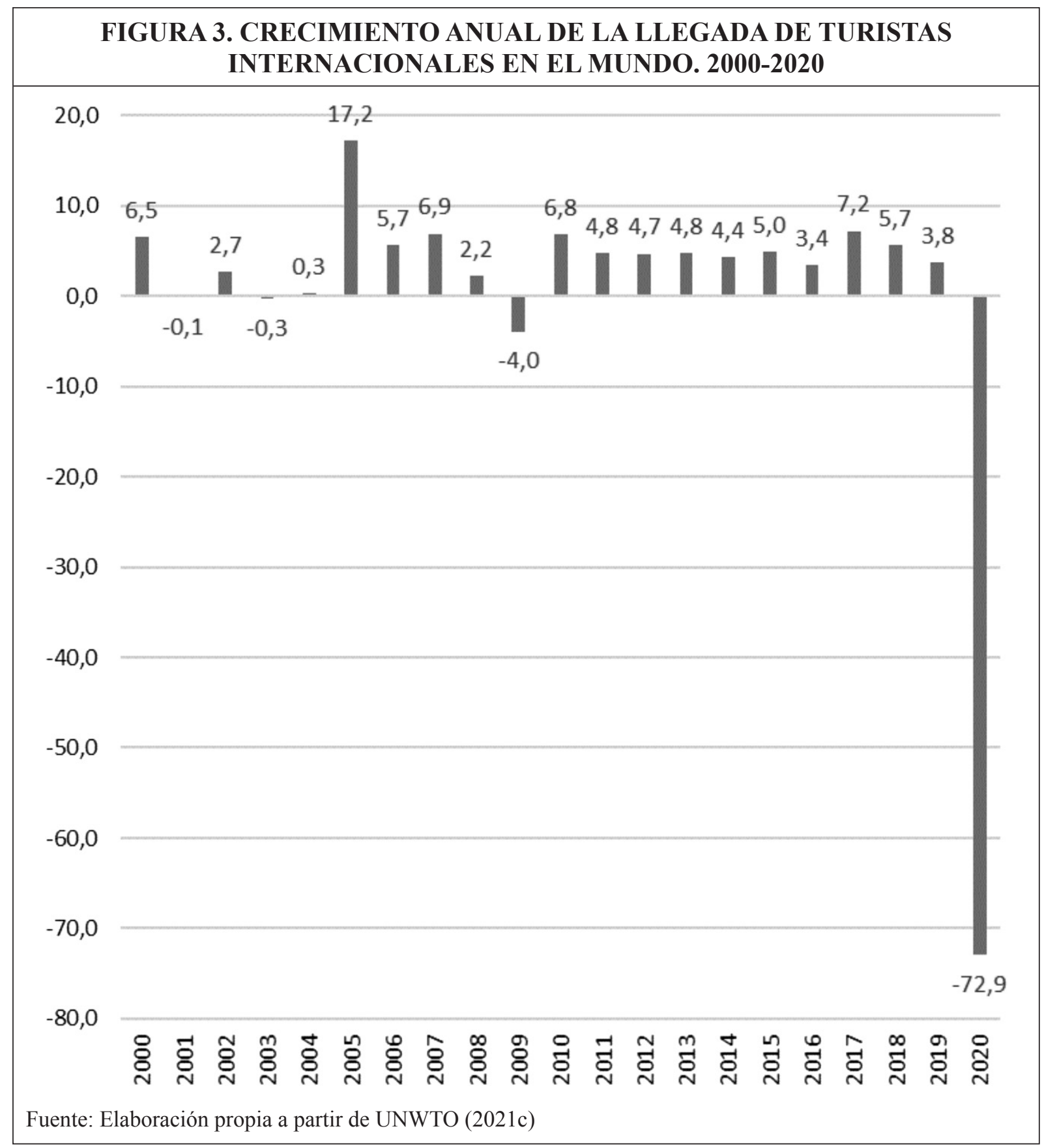

históricos de cada país. Este hecho fue puesto de manifiesto por Henderson (1999) al comparar los patrones de resiliencia que siguieron Indonesia y Tailandia para superar la crisis turística asociada a la crisis financiera asiática de 1997. En cualquier caso, los gobiernos ante una crisis turística sin precedentes decidieron dar una respuesta utilizando los instrumentos de la política económica.

\section{LAS RESPUESTAS DE LOS GOBIERNOS}

El marco inicial para la actuación en el ámbito turístico lo proporcionó la Organización Mundial del Turismo a las pocas semanas de declararse la pandemia. En un documento fechado en Madrid el 1 de abril de 2020 (UNWTO, 2020a) recoge una serie de recomendaciones que 
fueron preparadas con la participación de representantes de sus Estados Miembros, de la Organización Mundial de la Salud, y de otros organismos relacionados con el turismo (UNWTO, 2020b). En concreto, se detallaron 23 recomendaciones agrupadas en tres bloques: gestión de la crisis y mitigación de sus efectos; suministro de estímulos y aceleración de la recuperación; preparación para el futuro (Tabla 1). Sobre esa base, los gobiernos de los países construyeron sus respuestas de política económica.

Ahora bien, la crisis que ha provocado la pandemia no es solo turística. Ha afectado al conjunto de la economía con fuertes caídas de la producción y el empleo a nivel global (IMF, 2021). El 11 de marzo de 2020 la OMS declaró oficialmente la pandemia y, a los pocos meses, la mayoría de los gobiernos ya habían tomado medidas para amortiguar sus efectos y buscar la recuperación. En este sentido, la OMT analizó la respuesta de 220 países y territorios a la crisis

\section{TABLA 1. RECOMENDACIONES DE LA OMT PARA MITIGAR EL IMPACTO SOCIOECONÓMICO DE LA COVID-19 Y ACELERAR LA RECUPERACIÓN}

\begin{tabular}{|c|c|}
\hline $\begin{array}{l}\text { I. GESTIONAR LA CRISIS Y } \\
\text { MITIGAR EL IMPACTO }\end{array}$ & $\begin{array}{l}\text { 1. Incentivar la retención de puestos de trabajo, mantener el empleo por } \\
\text { cuenta propia y proteger a los grupos más vulnerables. } \\
\text { 2. Apoyar la liquidez de las empresas. } \\
\text { 3. Revisar los impuestos, tasas, gravámenes y normativas que afectan al } \\
\text { transporte y al turismo. } \\
\text { 4. Garantizar la protección del consumidor y la confianza. } \\
\text { 5. Promover el desarrollo de capacidades, en particular, de capacidades } \\
\text { digitales. } \\
\text { 6. Incluir el turismo en paquetes de emergencia económica nacionales, } \\
\text { regionales y mundiales. } \\
\text { 7. Crear mecanismos y estrategias de gestión de crisis. }\end{array}$ \\
\hline $\begin{array}{l}\text { II. SUMINISTRAR } \\
\text { ESTÍMULOS Y ACELERAR } \\
\text { LA RECUPERACIÓN }\end{array}$ & $\begin{array}{l}\text { 8. Proporcionar estímulos financieros para la inversión y las operaciones } \\
\text { en el sector del turismo. } \\
\text { 9. Revisar los impuestos, las tasas y las normativas que afectan a los } \\
\text { viajes y al turismo. } \\
\text { 10. Avanzar en la facilitación de los viajes. } \\
\text { 11. Promover la creación de nuevos puestos de trabajo y el desarrollo de } \\
\text { capacidades, especialmente digitales. } \\
\text { 12. Integrar la sostenibilidad ambiental en los paquetes de estímulo y } \\
\text { recuperación. } \\
\text { 13. Comprender el mercado y actuar con rapidez para restablecer la } \\
\text { confianza y estimular la demanda. } \\
\text { 14. Fomentar el marketing, los eventos y las reuniones } \\
\text { 15. Invertir en alianzas. } \\
\text { 16. Integrar el turismo en los programas nacionales, regionales e } \\
\text { internacionales de recuperación y en la asistencia para el desarrollo. }\end{array}$ \\
\hline $\begin{array}{l}\text { III. PREPARARSE PARA EL } \\
\text { MAÑANA }\end{array}$ & $\begin{array}{l}\text { 17. Diversificar los mercados, los productos y los servicios } \\
\text { 18. Invertir en los sistemas de inteligencia de mercados y la } \\
\text { transformación digital. } \\
\text { 19. Fortalecer la gobernanza del turismo a todos los niveles. } \\
\text { 20. Prepararse para la crisis, reforzar la resiliencia y velar por que } \\
\text { el turismo forme parte de los mecanismos y sistemas nacionales de } \\
\text { emergencia. } \\
\text { 21. Invertir en capital humano y desarrollo del talento. } \\
\text { 22. Situar el turismo sostenible en un lugar destacado de las agendas } \\
\text { nacionales. } \\
\text { 23. Efectuar la transición a la economía circular e incorporar los ODS. }\end{array}$ \\
\hline
\end{tabular}

Fuente: UNWTO (2020) 
y encontró que 167, es decir, más de un 75 por cien habían implementado medidas para tratar de superar la crisis turística (UNWTO, 2020c). Los gobiernos han enfrentado esta crisis con programas que afectan al conjunto de los sectores, aunque también se han articulado medidas específicas dirigidas al turismo. Por ello, quizás sea conveniente distinguir, como hace la OMT (UNWTO, 2020c), las acciones transversales de las que están orientadas al ámbito turístico. Sobre esa base, es posible ordenar la discusión agrupando las medidas en los siguientes ámbitos: fiscales y financieras; empleo; y otras medidas específicas para el turismo.

\subsection{Medidas fiscales $y$ financieras}

Los paquetes de estímulos fiscales fueron, en los primeros meses de la pandemia, los instrumentos más utilizados por los gobiernos. Con carácter general, han consistido en exenciones o aplazamientos de impuestos, fondos económicos de emergencia y asistencia económica, especialmente dirigidos a las PYMES, así como programas de inversión, facilidades para el pago de los servicios públicos a las empresas y asistencia a los grupos más vulnerables. También se articularon acciones similares dirigidas específicamente a las empresas relacionadas con la actividad turística. En esta línea, el caso de la Unión Europea es especialmente significativo. En julio de 2020 aprobó el programa denominado Next Generation EU dotado con 750.000 millones de euros para el periodo 2021-2026 y, paralelamente, se articularon distintas estrategias dirigidas a la recuperación del turismo en el que se implicaron los distintos niveles de gobierno (Sanabria-Díaz et al., 2021). Asimismo, resulta interesante mencionar las reducciones del IVA que llevaron a cabo algunos países (Alemania, Austria, Reino Unido, Hungría, entre otros). En este sentido, se ha argumentado que, en una situación en que los hogares han tenido pérdidas de empleos y limitaciones de acceso al crédito, los recortes o reducciones temporales del IVA podrían tener unos efectos estimuladores del consumo (Devereux et al., 2020).

Por su parte, las medidas de carácter financiero han estado orientadas, básicamente, a mantener la liquidez de las empresas facilitando créditos a tipos de interés reducidos, moratorias, y garantías públicas para el acceso a préstamos. En este caso, también se han creado líneas especialmente pensadas para las empresas turísticas y las compañías aéreas afectadas por la reducción del tráfico de pasajeros. A las PYMES se les suele dar un trato preferencial.

Tanto las acciones fiscales como financieras tuvieron como objetivo amortiguar el impacto inicial de la crisis protegiendo la actividad productiva. Casi el 90 por cien de los países que implementaron medidas lo hicieron en este ámbito (UNWTO, 2020c). No obstante, este tipo de programas no consiguió evitar que el PIB cayera con generalidad. Según el Fondo Monetario Internacional (IMF, 2021), durante 2020, la producción mundial descendió un 3,3 por cien, la de los países avanzados en un 4,7 por cien y, entre ellas, fue la de España la que registró el descenso más acusado, un 11 por cien, lo que concuerda con la información facilitada por la OCDE (Figura 2) y confirma la vulnerabilidad de los países dependientes del turismo a la crisis de la COVID-19. Por otro lado, el esfuerzo fiscal ha incrementado los déficits y la deuda pública y ha avivado la discusión sobre los riesgos y repercusiones futuras de esta estrategia (Makin y Layton, 2021).

\subsection{Empleo}

Como complemento a las medidas monetarias y fiscales, se pusieron en marcha acciones destinadas a tratar de mantener el empleo. En este sentido, se ha recurrido a toda la batería de instrumentos que ofrece la política económica convencional: permisos temporales a los trabajadores con salarios parcialmente financiados por el estado; subsidios directos a autónomos y microempresas; reducción o aplazamiento de los pagos a la seguridad social; prestaciones por 
desempleo; etc. Junto a estas medidas también se han implementado otras más innovadoras adaptadas a las circunstancias impuestas por la pandemia como el fomento del teletrabajo, la flexibilidad horaria, y los incentivos para la formación sobre la transformación digital.

Dado que el turismo es intensivo en el factor trabajo y, por tanto, es una fuente importante de empleo (Weinz et al., 2010), las autoridades públicas han implementado acciones concretas para el sector entre las que se encuentran ayudas para mantener los puestos de trabajo en las empresas turísticas (y, en particular, en la hostelería y en las compañías aéreas) y los programas de capacitación y formación en habilidades digitales. Aquí habría que recordar la importancia de mantener otro tipo de inversiones que, aunque, a veces, solo son rentables a largo plazo, determinan la competitividad y la productividad del turismo, como las relacionadas con la investigación y el desarrollo tecnológico (Romão y Nijkamp, 2019).

Ahora bien, cualquier valoración de las políticas de empleo son complejas ya que intervienen muchas variables y suelen presentar efectos colaterales que, con frecuencia, resultan contraproducentes. Pensemos, por ejemplo, en la reducción de las cuotas de la seguridad social. De acuerdo con el análisis económico elemental, dichas cuotas son un impuesto al trabajo que reduce la contratación e impone una brecha entre el salario que paga el empresario y el que recibe el trabajador. En principio, una reducción de la cuota tendrá un impacto que dependerá, no sólo de la cuantía de la reducción, sino también de las elasticidades de la oferta y de la demanda de trabajo (Brittain, 1971). Adicionalmente, las reducciones de las cuotas, no solo afectan a los ingresos fiscales, sino que alteran las decisiones de consumo y ahorro, transmitiéndose al conjunto de los mercados. El resultado final puede que no suponga un impacto apreciable sobre el empleo (Gruber,1997). Discusiones similares se pueden plantear respecto a cada una de las medidas que han implementado los gobiernos para tratar de mantener el empleo al considerar los efectos indirectos o indeseables que ocasionan (Benítez-Aurioles, 2021a).

\subsection{Otras medidas específicas para el turismo: conocimiento del mercado, colaboración público-privada, reactivación, y promoción del turismo nacional}

Además de las medidas de choque mencionadas en los apartados anteriores, los gobiernos fueron implementando otros tipos de estrategias. Así, entre las tendencias que se han acelerado con la pandemia, está la explotación del big data y de los sistemas inteligentes para avanzar en el conocimiento del mercado turístico (Stylos et al., 2021). Así, los cambios y la incertidumbre en torno a los patrones de viaje y reserva de alojamientos han estimulado la creación de grupos de trabajo, sistemas de seguimiento, elaboración de estudios y encuestas para recabar información y ajustar las futuras estrategias de marketing, tanto en el ámbito público como privado. En un contexto de alta volatilidad algunas organizaciones también se han implicado facilitando datos para el seguimiento de la evolución del mercado. Así, la Organización Mundial de Turismo ha activado lo que denomina el primer panel global para información turística que proporciona estadísticas e indicadores clave sobre el turismo receptor y emisor a nivel mundial, regional y nacional (UNWTO, 2021e). En la misma línea, el Consejo Mundial del Viaje y el Turismo, una organización que agrupa a representantes de los principales sectores del turismo a nivel global, ha creado un centro de información de acceso público (WTTC, 2021).

Por otro lado, aunque la colaboración público-privada en el ámbito del turismo posee cierta tradición que ha dado lugar a una literatura relativamente abundante sobre este asunto, incluidos algunos análisis críticos (Zapata y Hall, 2012), la pandemia le ha dado un nuevo impulso. La importancia de esta estrategia ha sido reconocida por algunos gobiernos con la creación de comités y plataformas de acción conjunta. De hecho, según la OMT, es probable que a medida que los países se concentren en acelerar la recuperación, se refuercen las alianzas público-privadas (UNWTO, 2020c). 
Las medidas de reactivación del turismo han consistido, al menos en un primer momento, en restaurar la confianza estableciendo protocolos y certificaciones sanitarias que garantizaran la seguridad de los turistas. Este es un asunto clave que condiciona la recuperación completa de la movilidad y, por tanto, de la actividad turística. Se ha convertido en una prioridad tanto para los gobiernos como para las empresas relacionadas con el turismo y, en particular, las que proporcionan alojamiento (Rodríguez-Antón y Alonso-Almeida, 2020). El debate sobre este tema es complejo en la medida en que los intereses en juego son múltiples y, a veces, difíciles de compatibilizar. Las simples recomendaciones de los gobiernos o las noticias difundidas por los medios de comunicación se pueden convertir en un instrumento para reorientar la demanda turística. Asimismo, la exigencia de certificados de vacunación para acceder a determinados destinos o instalaciones, o la obligatoriedad de realizar una cuarentena cuando se regresa de un viaje condicionan las opciones de los turistas. Todo ello nos recuerda lo obvio: superar la pandemia es una condición necesaria para la reactivación plena del turismo.

Por último, ante el retroceso experimentado por el turismo internacional, los gobiernos han puesto en marcha medidas para la promoción del turismo nacional. En este ámbito, ha sido frecuente la utilización de bonos para subvencionar el turismo de los residentes y, en particular, en alojamientos en hoteles o establecimientos similares. Este tipo de actuaciones se ha criticado con diferentes argumentos entre los que se encuentran las dudas que existen sobre su eficacia para incentivar los viajes, o la competencia que puede generarse entre territorios por atraer o retener el turismo nacional (Jiménez, 2021). En cualquier caso, la capacidad del turismo nacional para amortiguar la reducción del turismo internacional dependerá de la composición que, en cada caso, tenga la demanda turística (Arbulú et al., 2021).

\section{ANÁLISIS COMPARATIVO CON ESPECIAL REFERENCIA A ESPAÑA}

Una primera aproximación a la importancia que tienen las políticas implementadas en cada área geográfica lo encontramos en la Figura 4. Por encima de otras consideraciones menores destacan dos hechos significativos. En primer lugar, la utilización más frecuente de las políticas fiscales y financieras frente a las políticas de empleo. En todas las áreas geográficas el porcentaje de países que aplican medidas específicas destinadas a garantizar la liquidez de las empresas ha sido superior al de los que pusieron en marcha acciones específicas para garantizar el empleo. En segundo lugar, han sido los países europeos los que se han mostrado más inclinados a tomar medidas en comparación con otras áreas geográficas. En particular, en Europa, el 92 por cien de los países pusieron en marcha medidas fiscales y monetarias y el 73 por cien medidas relacionadas con el empleo.

Un análisis específico de las acciones implementadas por los gobiernos de los países europeos mediterráneos nos muestra una línea de actuación parecida, dentro de las especificidades de cada caso. Así, por ejemplo, el gobierno italiano aprobó desde marzo de 2020 distintos paquetes de medidas fiscales que, con carácter transversal, perseguían, entre otros objetivos, apoyar a las empresas a través de subvenciones, aplazamientos de impuestos y pagos de facturas de servicios públicos, así como facilitando la liquidez a través de garantías estatales a los créditos. Asimismo, dedicó recursos para garantizar la renta de los trabajadores despedidos y de los autónomos, y una suspensión de la cotización a la seguridad social para las nuevas contrataciones. De forma más específica se apoyó financieramente a las aerolíneas en dificultades y a los operadores de viajes y agencias de viajes, y se aprobaron subsidios para trabajadores de los sectores turístico y, más concretamente, se extendió los beneficios de la seguridad social a los trabajadores temporales del sector turístico.

Por su parte, el gobierno griego puso en marcha medidas similares destinadas a facilitar la liquidez de las empresas y el pago de obligaciones tributarias. En este contexto, se prestó especial 


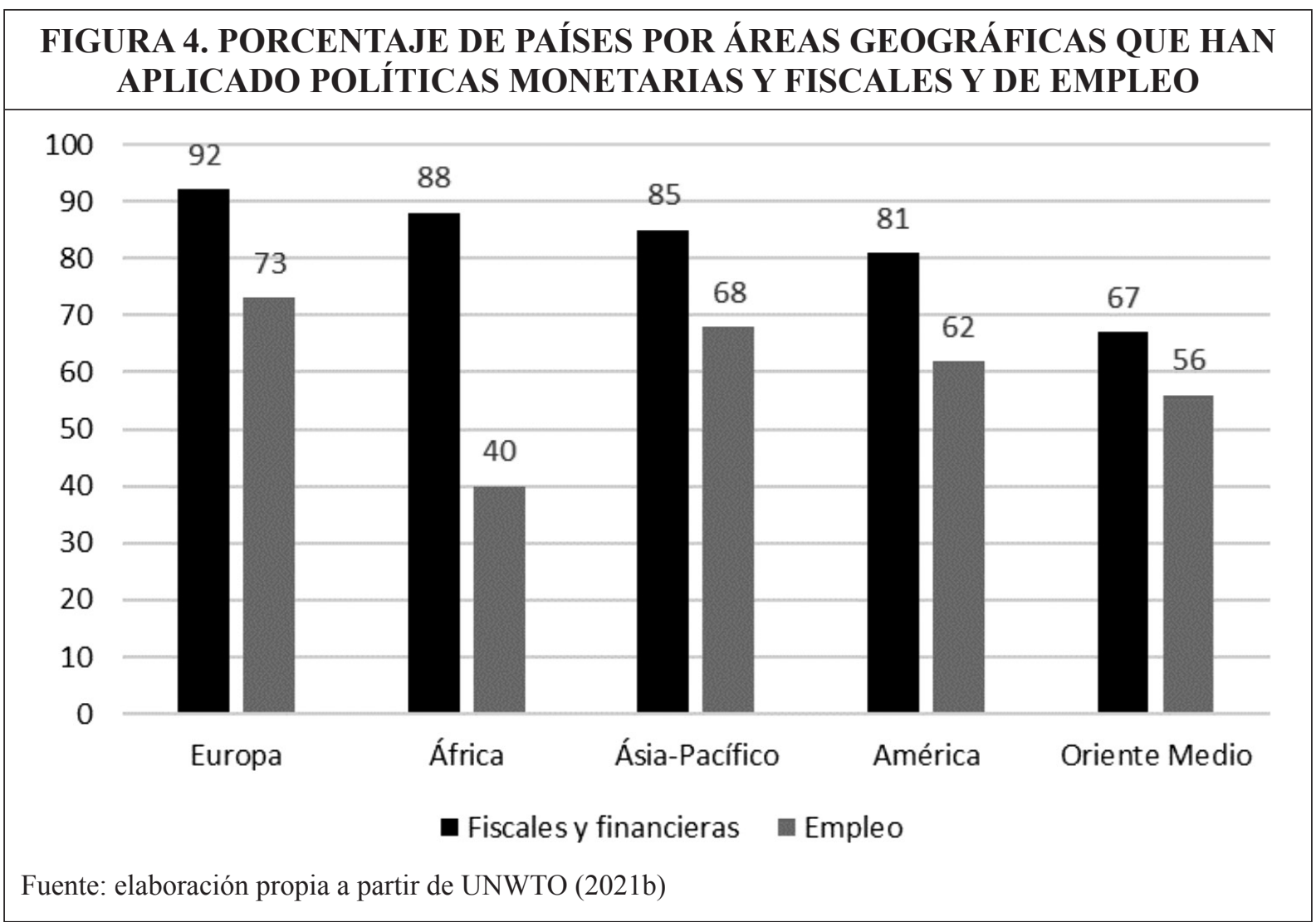

atención a las empresas turísticas que operan autobuses turísticos con subvenciones específicas. En cuanto a las medidas relacionadas con el empleo, se establecieron indemnizaciones para los trabajadores cuyos contratos laborales fueron suspendidos temporalmente a consecuencia de la pandemia. También se pusieron en marcha programas de asesoramiento, educación y certificación para desempleados con el fin de mejorar las habilidades de las personas que trabajan en las actividades turísticas.

En una línea similar podemos situar las acciones emprendidas por otros países del mediterráneo tanto europeos como no europeos como, por ejemplo, Marruecos y Egipto. No obstante, el caso de España es una buena referencia, dada la importancia que tiene el turismo en su economía, tanto en términos absolutos como relativos, para analizar la política económica que, específicamente, se ha implementado para hacer frente a la crisis turística de la COVID-19.

Al margen de las actuaciones de los gobiernos regionales y locales, el gobierno español presentó en junio de 2020 el Plan de impulso para el sector turístico: hacia un turismo seguro y sostenible (Gobierno de España, 2020). Una primera aproximación al contenido del Plan la podemos realizar a través de la Figura 5 que recoge la nube de palabras del documento como resultado de la aplicación del programa WordClouds, disponible en Internet (https:// www.wordclouds.com/). Entre las palabras más utilizadas está "empresas" lo que sugiere una atención especial al ámbito empresarial.

El Plan se organiza en torno a cinco pilares: recuperar la confianza en el destino; medidas para la reactivación del sector; mejora de la competitividad del destino turístico; mejora del modelo de conocimiento integral; marketing y promoción. Cada uno de ellos, a su vez, consta de 28 medidas en total (Tabla 2). Una simple lectura del enunciado de las medidas permite encontrar una clara correspondencia con la propuesta general que hizo la OMT recogida en la Tabla 1 y analizada en el apartado anterior. 


\author{
FIGURA 5. NUBE DE PALABRAS DEL PLAN DE IMPULSO \\ PARA EL SECTOR TURÍSTICO
}

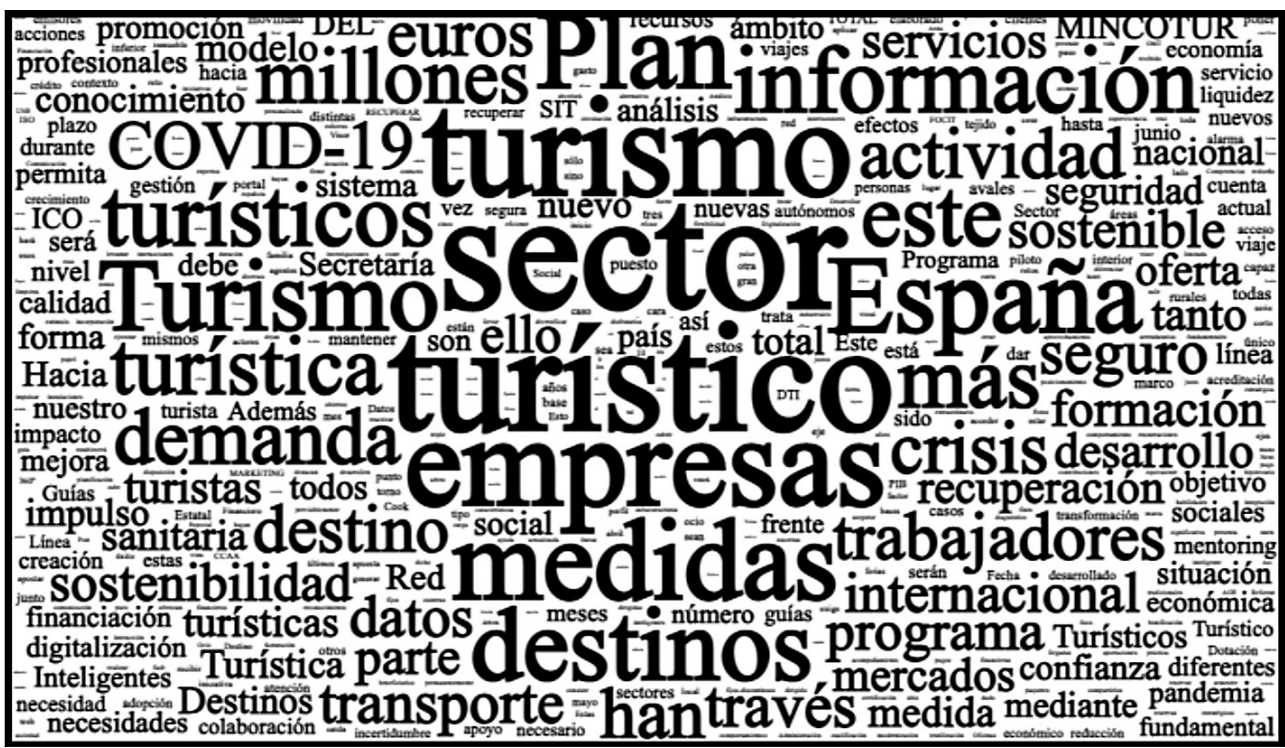

Fuente: elaboración propia a partir de Gobierno de España (2020)

\begin{tabular}{|c|c|c|c|}
\hline \multicolumn{4}{|c|}{$\begin{array}{l}\text { TABLA 2. DOTACIÓN ECONÓMICA DE LAS MEDIDAS DEL } \\
P L A N D E I M P U L S O P A R A E L S E C T O R T U R I ́ S T I C O\end{array}$} \\
\hline PILARES & Medidas & Millones $\square$ & $\%$ \\
\hline \multirow{4}{*}{$\begin{array}{l}\text { I. RECUPERAR LA } \\
\text { CONFIANZA EN EL } \\
\text { DESTINO }\end{array}$} & Guías para la reducción del contagio en el sector turístico & 0,2 & 0,005 \\
\hline & Medidas para adaptar el transporte público como medio seguro &.. & \\
\hline & Distintivo "Safe Tourism" & .. & \\
\hline & $\begin{array}{l}\text { Programa piloto para el establecimiento de "corredores } \\
\text { turísticos seguros" }\end{array}$ &. & \\
\hline \multirow{3}{*}{$\begin{array}{l}\text { II. MEDIDAS } \\
\text { PARA LA } \\
\text { REACTIVACIÓN } \\
\text { DEL SECTOR }\end{array}$} & Medidas laborales & .. & \\
\hline & $\begin{array}{l}\text { Programa de formación, capacitación y mentoring para el } \\
\text { sector turístico }\end{array}$ & 106,4 & 2,495 \\
\hline & Liquidez y solvencia empresarial & 3.256 & 76,382 \\
\hline \multirow{4}{*}{$\begin{array}{l}\text { III. MEJORA DE LA } \\
\text { COMPETITIVIDAD } \\
\text { DEL DESTINO } \\
\text { TURÍSTICO }\end{array}$} & $\begin{array}{l}\text { Fondo Financiero del Estado para la Competitividad } \\
\text { Turística (FOCIT) }\end{array}$ & 515 & 12,08 \\
\hline & $\begin{array}{l}\text { Financiación de proyectos para la digitalización, innovación } \\
\text { e internacionalización del sector turístico }\end{array}$ & 216 & 5,067 \\
\hline & Programa de Planes de Sostenibilidad Turística en Destinos & 53 & 1,243 \\
\hline & Reforzar la Red de Destinos Turísticos Inteligentes & 75 & 1,759 \\
\hline \multirow{3}{*}{$\begin{array}{l}\text { IV. MEJORA DEL } \\
\text { MODELO DE } \\
\text { CONOCIMIENTO } \\
\text { INTEGRAL }\end{array}$} & $\begin{array}{l}\text { Análisis de la demanda internacional mediante el refuerzo en } \\
\text { la información de los mercados }\end{array}$ & 1,6 & 0,038 \\
\hline & $\begin{array}{l}\text { Refuerzo del Sistema de Inteligencia Turística (SIT) para el } \\
\text { análisis de demanda y oferta turísticas nacionales }\end{array}$ & 1,5 & 0,035 \\
\hline & Creación de un Visor de Datos de Turismo &.. & \\
\hline \multirow{3}{*}{$\begin{array}{l}\text { V. MARKETING Y } \\
\text { PROMOCIÓN }\end{array}$} & Plan de Marketing 2020 - 2024 TURESPAÑA & 33,3 & 0,781 \\
\hline & Mejora de herramientas promoción y marketing & 4,8 & 0,112 \\
\hline & & $4.262,8$ & 100 \\
\hline
\end{tabular}


La concreción económica que contiene el Plan implementado en España y que, por motivos evidentes, no realizó la OMT, introduce datos interesantes para el análisis. En efecto, solo tres medidas absorben más del 90 por cien de los 4.262,8 millones de euros con el que se ha dotado el plan. La medida destinada a garantizar la liquidez y solvencia empresarial representa el 76,4 por cien del montante total. Ahora bien, debe tenerse en cuenta que, dentro de esta partida, se incluye la línea de avales del ICO, con un sub-tramo preferente por importe de 2.500 millones de euros para el sector turístico, que, en realidad, solo supondría un desembolso presupuestario si los prestatarios se declaran insolventes. Asimismo, el Fondo Financiero del Estado para la Competitividad Turística (FOCIT), que supone el 12 por cien de la dotación del plan, son préstamos a empresas turísticas. Lo mismo ocurre con la medida destinada a la Financiación de proyectos para la digitalización, innovación e internacionalización del sector turístico, que representa algo más del 5 por cien del Plan.

En cierto sentido, el Plan es un complemento de las medidas transversales que el gobierno español implementó como respuesta a la pandemia. Esas medidas también afectaron a las empresas del sector turístico en la cuantía que refleja la Tabla 3. En concreto, son 15.263 millones de euros de los cuales el 70 por cien, aproximadamente, son avales para préstamos.

El propio Plan suma las cantidades totales de las Tablas 2 y 3 para afirmar lo siguiente: "como prueba inequívoca del firme compromiso del Gobierno de España con un sector estratégico para nosotros como es el sector turístico, se comprometerán 19.535 millones de euros de ayudas para el conjunto de empresas, la inmensa mayoría pymes, y para sus trabajadores y trabajadoras" (Gobierno de España, 2021, p. 9).

En consecuencia, al menos en el caso de España, la política económica destinada a combatir la crisis de la COVI-19 ha consistido, básicamente, en tratar de garantizar la solvencia y liquidez de las empresas turísticas facilitando el acceso a la financiación. Junto a esta línea de actuación se han implementado otras medidas que, a juzgar por su dotación económica, tienen un impacto menor y, en algunos casos, testimonial. Precisamente, muchas de esas otras medidas conformaban las líneas prioritarias de las Directrices Generales de la Estrategia de Turismo Sostenible de España 2030 elaborado antes de la pandemia (Gobierno de España, 2019).

Resulta destacable que el diagnóstico del sector que contiene las Directrices se realiza a través de un análisis DAFO. Pues bien, entre las amenazas señaladas no se menciona la aparición de una potencial pandemia que, de hecho, ha sido el elemento más disruptivo en la evolución del turismo y nos confirma las debilidades de los escenarios prospectivos.

TABLA 3. MEDIDAS DE CHOQUE GENERALES
QUE AFECTARON AL SECTOR TURÍSTICO
\begin{tabular}{|l|l|l|}
\hline \multicolumn{2}{|c|}{} & Millones de \\
\hline $\begin{array}{l}\text { Extensión temporal de ERTE en condiciones especiales para el sector } \\
\text { turístico }\end{array}$ & 3.450 & $\%$ \\
\hline $\begin{array}{l}\text { Extensión temporal de la prestación extraordinaria por cese de } \\
\text { actividad para autónomos del sector turístico }\end{array}$ & 628 & 22,59 \\
\hline Línea de avales del ICO & 10.524 & 4,11 \\
\hline Línea ICO Thomas Cook/COVID-19 & 400 & 68,91 \\
\hline Aplazamiento de impuestos & 271 & 2,62 \\
\hline TOTAL & 15.273 & 1,77 \\
\hline Fuente: Gobierno de España (2020) & 100,00 \\
\hline
\end{tabular}


Es lógico que la profunda crisis turística asociada a la COVID-19 exija, a corto plazo, acciones destinadas a amortiguar el impacto sobre las empresas, tal como se ha hecho. No obstante, a medio y largo plazo, el objetivo declarado de las Directrices sigue vigente: "sentar las bases de la transformación del turismo español hacia un modelo de crecimiento sostenido y sostenible, que nos permita mantener su posición de liderazgo mundial" (Gobierno de España, 2019, p. 11). En este contexto, los ejes y líneas de actuación marcadas en las Directrices (Tabla 4) es probable que vuelvan a configurar la política turística en la era post-COVID.

Con la información disponible no es posible determinar hasta qué punto las acciones emprendidas por las distintas administraciones públicas han contribuido a la recuperación de la actividad turística. No obstante, existen algunas señales que muestran la resiliencia del turismo, al menos en España. Una vez eliminados los datos entre abril y junio de 2020 debido a la excepcional situación que supuso la declaración del estado de alarma el 14 de marzo que se prolongó hasta el 21 de junio, observamos algunos signos de recuperación si atendemos a las pernoctaciones en los hoteles y al empleo (Figura 6). Durante los meses de verano de 2020 se produce un repunte en el número de pernoctaciones que, posteriormente, decrece por motivos estacionales hasta que al comienzo del verano de 2021 vuelve a aumentar con gran intensidad. Además, existe otra característica que supone un hecho insólito: las pernoctaciones hoteleras de los residentes en España superan a las de los residentes en el extranjero durante 15 meses consecutivos, desde mayo de 2020 hasta agosto de 2021. En septiembre de 2021 las de los extranjeros vuelven a superar, levemente, a la de los nacionales. En cualquier caso, el aumento del turismo que los residentes en España realizan en el propio país es el que explica la recuperación turística. Todo

\section{TABLA 4. EJES Y LÍNEAS DE ACTUACIÓN DE DIRECTRICES GENERALES} DE LA ESTRATEGIA DE TURISMO SOSTENIBLE DE ESPAÑA 2030

\begin{tabular}{|c|c|}
\hline EJES & LÍNEAS DE ACTUACIÓN \\
\hline \multirow{3}{*}{$\begin{array}{l}\text { I. GOBERNANZA } \\
\text { COLABORATIVA }\end{array}$} & Impulsar las herramientas de gobernanza \\
\hline & Desarrollar la política territorial \\
\hline & Aumentar desde el turismo la influencia internacional de España \\
\hline \multirow{4}{*}{$\begin{array}{l}\text { II. CRECIMIENTO } \\
\text { SOSTENIBLE }\end{array}$} & Impulsar el desarrollo equilibrado del turismo en el territorio \\
\hline & Impulsar la sostenibilidad como valor de marca del turismo español \\
\hline & Sostenibilidad de la demanda \\
\hline & Reducir las externalidades negativas de la actividad turística \\
\hline \multirow[t]{4}{*}{$\begin{array}{l}\text { III. TRANSFORMACIÓN } \\
\text { COMPETITIVA }\end{array}$} & $\begin{array}{l}\text { Fortalecer el ecosistema público-privado de impulso a la transformación } \\
\text { competitiva }\end{array}$ \\
\hline & Desplegar una estrategia digital para el sector turismo \\
\hline & Desarrollar las normas públicas para la transformación digital \\
\hline & Impulsar la adaptación de la regulación existente al nuevo entorno turístico \\
\hline \multirow{3}{*}{$\begin{array}{l}\text { IV. ESPACIO } \\
\text { TURÍSTICO, EMPRESAS } \\
\text { Y PERSONAS }\end{array}$} & $\begin{array}{l}\text { Dotar al territorio de nuevas capacidades, infraestructuras y recursos de } \\
\text { gestión }\end{array}$ \\
\hline & Impulsar la calidad del turismo español \\
\hline & Promover una mayor calidad del empleo turístico \\
\hline \multirow{4}{*}{$\begin{array}{l}\text { V. PRODUCTO, } \\
\text { MARKETING E } \\
\text { INTELIGENCIA } \\
\text { TURÍSTICA }\end{array}$} & $\begin{array}{l}\text { Potenciar estrategias de promoción turística diferenciadas según tipología } \\
\text { de mercados emisores }\end{array}$ \\
\hline & Desarrollar una propuesta de valor singular, dinámica y competitiva \\
\hline & Desarrollar un modelo de inteligencia turística basado en los datos \\
\hline & Reforzamiento de la estrategia de marketing digital \\
\hline
\end{tabular}

Fuente: Gobierno de España (2019) 
apunta a que los españoles sustituyeron los viajes internacionales por los nacionales facilitando la recuperación de la actividad turística (Benítez-Aurioles, 2021b). De hecho, los 19,6 millones de pernoctaciones hoteleras de los residentes en España en agosto de 2021 suponen un record que nunca antes se había alcanzado. Este dato refuerza el papel del turismo nacional para compensar la caída del turismo internacional en España (Arbulú et al., 2021) y, por tanto, la oportunidad de las acciones dirigidas a estimular el turismo interior que se han venido implementando. No obstante, a pesar de estos signos de mejora, la atonía de la demanda turística internacional ha impedido que el personal empleado en los hoteles alcance las cifras previas a la pandemia.

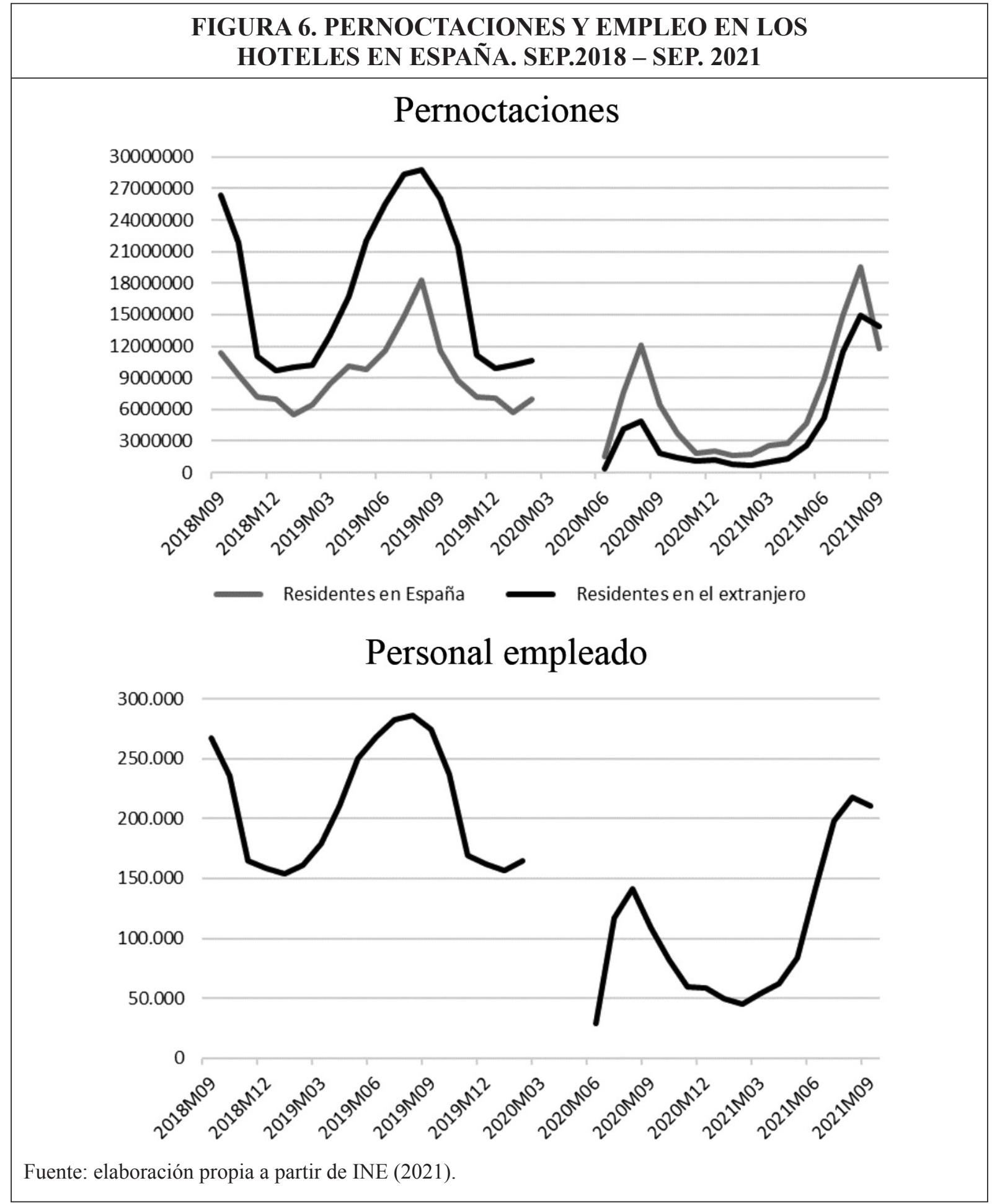




\section{CONCLUSIONES}

Los datos demuestran de una manera irrefutable que la COVID-19 ha colapsado el mercado turístico provocando una crisis descomunal. En este contexto de grave recesión global, los países más vulnerables fueron aquellos con mayor dependencia de la actividad turística. Para combatir esta situación los gobiernos implementaron políticas económicas transversales junto a otras específicamente orientadas hacia el sector turístico. A corto plazo el protagonismo ha recaído en las acciones convencionales destinadas a tratar de mantener la liquidez y solvencia de las empresas facilitando el acceso al crédito en condiciones preferentes y, en particular, a través de la concesión de garantías públicas. Este tipo de instrumentos se ha utilizado en el pasado y han demostrado su eficacia, reduciendo los costes de ajustes de las empresas y las caídas de la producción y del empleo. También son destacables las políticas dirigidas a amortiguar el impacto que ha tenido la pandemia sobre la renta de los trabajadores.

No obstante, las dimensiones de la crisis turística de la COVID-19 exige prudencia a la hora de extrapolar los resultados de las políticas implementadas en el pasado. En cualquier caso, existen análisis que demuestran que las actuaciones públicas destinadas a garantizar la liquidez de las empresas reducen la tasa de fracaso empresarial entre las PYMES y, especialmente, las relacionadas con las actividades turísticas (Kalemli-Ozcan et al., 2020). El problema está en que no resulta fácil distinguir entre las empresas que serán viables a largo plazo de las que no lo son, incluso con ayudas públicas, lo que plantea un debate sobre la capacidad de la política económica para disminuir los costes sociales de la pandemia (De la Fuente et al., 2021). Incluso es probable que se produzcan cambios permanentes en los patrones de viaje y alojamiento de los turistas que exijan modificaciones profundas que no estén al alcance de todas las empresas. En esos casos, ayudar a empresas que están condenadas a abandonar el mercado retrasaría la reasignación de los factores productivos y comprometería la rentabilidad social de los recursos públicos.

A medio plazo parece conveniente ceder el protagonismo a las medidas basadas en la promoción de los destinos turísticos. En este sentido, es posible que se reavive la competencia entre países por atraer a los turistas internacionales. Más discutibles son las campañas de los gobiernos regionales y locales por atraer o retener a los turistas nacionales. Si se acepta que la iniciativa en las campañas de promoción turística, destinadas a la recuperación tras una crisis, debe ser pública entonces habría que plantear el debate sobre la coordinación entre administraciones ya que, en algunos casos, todos los niveles de la administración (central, regional y local) tienen competencias sobre la promoción turística. Por ejemplo, en España la Secretaría de Estado de Turismo ejerce la función de promoción exterior del turismo; las Comunidades Autónomas también asumen competencias, reconocidas en sus Estatutos, sobre la promoción (interna y externa) del turismo; y las provincias y municipios, según algunas normas autonómicas tienen, asimismo, competencias en materia de promoción turística. Si a ello añadimos la potencial competencia entre regiones por atraer turistas, que puede desembocar en un juego de suma cero (Downie, 2006), o los posibles efectos desbordamiento (spillovers) de las campañas de promoción (Bergholz, 2018), el tema se complica. En cualquier caso, la colaboración público-privada y el concurso de los medios de comunicación resultan pertinentes para recuperar la confianza de los turistas.

A más largo plazo, una vez superada la pandemia, cabría retomar y actualizar las estrategias para el turismo y el papel que deben desempeñar las autoridades públicas. Habría que recordar que la demanda turística depende, no sólo de los servicios que ofrecen las empresas, sino de atributos que son públicos. Desde un punto de vista social, el estado estaría legitimado a regular el acceso a los recursos públicos que consumen los turistas para garantizar su sostenibilidad. En este sentido, la crisis turística provocada por la pandemia es una excelente oportunidad para diseñar estrategias que permitan a las empresas turísticas crear riqueza y empleo de calidad compatibles con las preferencias del conjunto de la sociedad. 
Para finalizar debemos reconocer las limitaciones del trabajo realizado que, al mismo tiempo, se convierten en potenciales proyectos de investigación. Nuestro análisis ha sido, fundamentalmente, descriptivo basado en políticas económicas anunciadas. Una vez que las acciones se ejecuten, definitivamente, será necesario una evaluación de la eficacia que han tenido. En principio, los datos disponibles para el caso de España apuntan a que se ha producido una cierta recuperación de la actividad turística, protagonizada por los turistas nacionales. No obstante, para cuantificar la contribución de las políticas implementadas para superar la crisis turística de la COVID-19 será necesario, en primer término, esperar a que se cumplan los plazos establecidos para su vigencia y, sobre esa base, aplicar las técnicas que proporciona el análisis económico, incluidos los modelos de equilibrio general computable. Esta tarea plantea numerosas dificultades, pero, al mismo tiempo, es irrenunciable porque, si pretendemos que las discusiones en torno a la política económica sean productivas, necesariamente deben venir acompañadas de valoraciones cuantitativas.

\section{BIBLIOGRAFÍA}

Arbulú, I., Razumova, M., Rey-Maquieira, J., y Sastre, F. (2021). Can domestic tourism relieve the COVID-19 tourist industry crisis? The case of Spain. Journal of Destination Marketing \& Management, 20, 100568.

Beirman, D. (2003). Restoring tourism destinations in crisis: A strategic marketing approach. Wallingford: CABI Publishing

Bénassy-Quéré, A., Blanchard, O., Coeuré, B., Jacquet, P., y Pisani-Ferry, J. (2021). Politique Économique. Louvain-la-Neuve: De Boeck supérieur. $4^{\mathrm{a}}$ edición.

Benítez-Aurioles, B. (2019). Barcelona's peer-to-peer tourist accommodation market in turbulent times: terrorism and political uncertainty. International Journal of Contemporary Hospitality Management, 31(12), 4419-4437.

Benítez-Aurioles, B. (2020). Tourism Resilience Patterns in Southern Europe. Tourism Analysis, 25(4), 409-424.

Benítez-Aurioles, B. (2021a). Política de empleo: posibilidades y limitaciones. International Review of Economic Policy-Revista Internacional de Política Económica, 3(1), 20-40.

Benítez-Aurioles, B. (2021b). El turismo interior en España ante la crisis de la COVID-19. Boletín económico de ICE, Información Comercial Española, (3139), 43-53.

Bergholz, C. (2018). Inter-municipal cooperation in the case of spillovers: evidence from Western German municipalities. Local Government Studies, 44(1), 22-43,

Blake, A., y Sinclair, M. T. (2003). Tourism crisis management: US response to September 11. Annals of Tourism Research, 30(4), 813-832.

Brittain, J.A. (1971). The incidence of social security payroll taxes. The American Economic Review, 61(1), 110-125

Carlsen, J. C., y Hughes, M. (2008). Tourism market recovery in the Maldives after the 2004 Indian Ocean tsunami. Journal of Travel \& Tourism Marketing, 23(2-4), 139-149.

Casado, M. A. (1998). Peru's tourism industry: Growth, setbacks, threats. The Cornell Hotel and Restaurant Administration Quarterly, 39(1), 68-73.

Chacko, H., y Marcell, M. (2008). Repositioning a tourism destination. Journal of Travel \& Tourism Marketing, 23(2-4), 223-235.

Chan, C. S., Nozu, K., y Cheung, T. O. L. (2020). Tourism and natural disaster management process: perception of tourism stakeholders in the case of Kumamoto earthquake in Japan. Current Issues in Tourism, 23(15), 1864-1885.

Ciocco, L., y Michael, E. (2007). Hazard or disaster: Tourism management for the inevitable in Northeast Victoria. Tourism Management, 28(1), 1-11. 
Cooper, M. (2006) Japanese Tourism and the SARS Epidemic of 2003. Journal of Travel \& Tourism Marketing, 19(2-3), 117-131

Corbet, S., O’Connell, J. F., Efthymiou, M., Guiomard, C., y Lucey, B. (2019). The impact of terrorism on European tourism. Annals of Tourism Research, 75, 1-17.

Cuadrado, J.R. (Dir.) (2019). Política Económica. Elaboración, objetivos e instrumentos. Madrid: McGraw-Hill. $6^{\text {a }}$ ed.

De la Fuente, Á., Arruñada, B., Bermejo, N., Cerqueira, O., Martínez, M. C., Seijo, J. M. F., \& Sanz, J. R. (2021). Cómo ayudar a las empresas en la crisis del Covid. FEDEA Policy Papers, 5, 1-34.

Devereux, M. P., Güçeri, İ., Simmler, M., y Tam, E. H. (2020). Discretionary fiscal responses to the COVID-19 pandemic. Oxford Review of Economic Policy, 36(Supplement_1), S225-S241.

Drisko, J. W., \& Maschi, T. (2016). Content analysis. Oxford: Oxford University Press.

Downie, C. (2006). State and territory tourism assistance. Australia Institute. https://www. researchgate.net/profile/Christian-Downie/publication/237377469_State_and territory_tourism_assistance_A_zero_sum_game/links/55de9df508ae79830bb58e17/ State-and-territory-tourism-assistance-A-zero-sum-game.pdf

Gobierno de España (2019). Directrices Generales de la Estrategia de Turismo Sostenible de España 2030. https:/www.segittur.es/wp-content/uploads/2021/02/DirectricesGenerales-de-la-Estrategia-de-Turismo-Sostenible-de-Espana-2030.pdf

Gobierno de España (2020). Plan de impulso para el sector turístico: hacia un turismo seguro $y$ sostenible. https://www.lamoncloa.gob.es/serviciosdeprensa/notasprensa/industria/ Documents/2020/20062020_PlanTurismo.pdf

Gruber, J. (1997). The incidence of payroll taxation: evidence from Chile. Journal of Labor Economics, 15(S3), S72-S101.

Gu, H., y Wall, G. (2006). SARS in China: Tourism impacts and market rejuvenation. Tourism Analysis, 11(6), 367-379.

Guo, Y., Zhang, J., Zhang, Y., y Zheng, C. (2018). Examining the relationship between social capital and community residents' perceived resilience in tourism destinations. Journal of Sustainable Tourism, 26(6), 973-986.

Holm, M. R., Lugosi, P., Croes, R. R., y Torres, E. N. (2017). Risk-tourism, risk-taking and subjective well-being: A review and synthesis. Tourism Management, 63, 115-122.

Huang, J. H., y Min, J. C. (2002). Earthquake devastation and recovery in tourism: The Taiwan case. Tourism Management, 23(2), 145-154.

IMF (2021). World Economic Outlook. Managing Divergent Recoveries. Washington: International Monetary Fund, Publication Services.

INE (2021). Encuesta de Ocupación Hotelera. https://ine.es/dyngs/INEbase/es/operacion. $\mathrm{htm} ? \mathrm{c}=$ Estadistica_C\&cid=1254736177015\&menu=ultiDatos\&idp=1254735576863

Jafari, J., \& Ritchie, J. B. (1981). Toward a framework for tourism education: Problems and prospects. Annals of tourism research, 8(1), 13-34.

Jiménez, J.L. (2021). Bonos turísticos (o cómo malgastar dinero público). https://nadaesgratis. es/juan-luis-jimenez/bonos-turisticos-o-como-malgastar-dinero-publico

Jimeno, J.F. (2021). Presentación La evaluación de las políticas públicas en España: recursos, metodologías y algunos ejemplos. Cuadernos Económicos de ICE, 102, 5-11.

Joppe, M. (2018). Tourism policy and governance: Quo vadis? Tourism management perspectives, 25, 201-204.

Kalemli-Ozcan, S., Gourinchas, P. O., Penciakova, V. y Sander, N. (2020). COVID-19 and SME Failures. IMF Working Paper no. 20/27. Washington D.C. https://www.imf.org/en/ Publications/WP/Issues/2020/09/25/COVID-19-and-SME-Failures-49753 
Khalid, U., Okafor, L. E., y Burzynska, K. (2021). Does the size of the tourism sector influence the economic policy response to the COVID-19 pandemic? Current Issues in Tourism, $1-20$.

Mair, J., Ritchie, B. W., y Walters, G. (2016). Towards a research agenda for post-disaster and post-crisis recovery strategies for tourist destinations: A narrative review. Current Issues in Tourism, 19(1), 1-26.

Makin, A. J., y Layton, A. (2021). The global fiscal response to COVID-19: Risks and repercussions. Economic Analysis and Policy, 69, 340-349.

Mandić, A., Mrnjavac, Ž., y Kordić, L. (2018). Tourism infrastructure, recreational facilities and tourism development. Tourism and Hospitality Management, 24(1), 41-62.

McKercher, B., y Chon, K. (2004). The over-reaction to SARS and the collapse of Asian tourism. Annals of Tourism Research, 31(3), 716-719.

Murphy, P. E., y Bayley, R. (1989). Tourism and disaster planning. Geographical Review, 79(1), 36-46.

Netto, A. P. (2009). What is tourism? Definitions, theoretical phases and principles. In J. Tribe (ed)., Philosophical issues in tourism (pp. 43-61). Bristol: Channel View Publications.

OCDE (2021). Statistics. https://www.oecd-ilibrary.org/statistics

Orchiston, C., y Higham, J. E. S. (2016). Knowledge management and tourism recovery (de) marketing: The Christchurch earthquakes 2010-2011. Current Issues in Tourism, 19(1), 64-84.

Pechlaner, H., y Frehse, J. (2010). Financial crisis and tourism. In Trends and Issues in Global Tourism 2010 (pp. 27-38). Berlin, Heidelberg: Springer

Presenza, A., y Cipollina, M. (2010). Analysing tourism stakeholders networks. Tourism Review, 65(4), 17-30.

Ritchie, B. W., y Jiang, Y. (2019). A review of research on tourism risk, crisis and disaster management: Launching the annals of tourism research curated collection on tourism risk, crisis and disaster management. Annals of Tourism Research, 79, 102812.

Robinson, L., y Jarvie, J. K. (2008). Post-disaster community tourism recovery: the tsunami and Arugam Bay, Sri Lanka. Disasters, 32(4), 631-645.

Rodríguez-Antón, J. M., y Alonso-Almeida, M. D. M. (2020). COVID-19 impacts and recovery strategies: The case of the hospitality industry in Spain. Sustainability, 12(20), 8599.

Romão, J., y Nijkamp, P. (2019). Impacts of innovation, productivity and specialization on tourism competitiveness-a spatial econometric analysis on European regions. Current Issues in Tourism, 22(10), 1150-1169.

Rosselló, J., Becken, S., y Santana-Gallego, M. (2020). The effects of natural disasters on international tourism: A global analysis. Tourism Management, 79, 104080.

Sanabria-Díaz, J. M., Aguiar-Quintana, T., y Araujo-Cabrera, Y. (2021). Public strategies to rescue the hospitality industry following the impact of COVID-19: A case study of the European Union. International Journal of Hospitality Management, 102988.

Schmude, J., Zavareh, S., Schwaiger, K. M., y Karl, M. (2018). Micro-level assessment of regional and local disaster impacts in tourist destinations. Tourism Geographies, 20(2), 290-308.

Sharpley, R., y Craven, B. (2001). The 2001 foot and mouth crisis-rural economy and tourism policy implications: a comment. Current Issues in Tourism, 4(6), 527-537.

Sheller, M. (2021). Reconstructing tourism in the Caribbean: connecting pandemic recovery, climate resilience and sustainable tourism through mobility justice. Journal of Sustainable Tourism, 29(9), 1436-1449.

Stylos, N., Zwiegelaar, J., y Buhalis, D. (2021). Big data empowered agility for dynamic, volatile, and time-sensitive service industries: the case of tourism sector. International Journal of Contemporary Hospitality Management, 33(3), 1015-1036. 
Thompson, D., Muriel, P., Russell, D., Osborne, P., Bromley, A., Rowland, M., Creigh-Tyte, S., y Brown, C. (2002). Economic costs of the foot and mouth disease outbreak in the United Kingdom in 2001. Revue Scientifique et Technique (International Office of Epizootics), 21(3), 675-687.

Tomczewska-Popowycz, N., y Quirini-Popławski, Ł. (2021). Political instability equals the collapse of tourism in Ukraine?. Sustainability, 13(8), 4126.

Tsai, C. H., y Chen, C. W. (2010). An earthquake disaster management mechanism based on risk assessment information for the tourism industry-a case study from the island of Taiwan. Tourism Management, 31(4), 470-481.

UNWTO (2020a). La OMT lanza un llamamiento a la acción para la mitigación del impacto de la covid-19 en el turismo y la recuperación del sector. https://webunwto.s3.eu-west-1. amazonaws.com/s3fs-public/2020-04/200401\%20-\%20Call\%20for\%20Action $\% 20$ for $\% 20$ Tourism $\% \mathrm{E} 2 \% 80 \% 99 \mathrm{~s} \% 20 \mathrm{COVID}-19 \% 20 \mathrm{ES}$.pdf

UNWTO (2020b). Apoyo al empleo y a la economía a través de los viajes y el turismo. https://webunwto.s3.eu-west-1.amazonaws.com/s3fs-public/2020-04/ COVID19_Recommendations_ES.pdf

UNWTO (2020c). How are countries supporting tourism recovery? https://www.e-unwto.org/ doi/epdf/10.18111/9789284421893

UNWTO (2021a). Glosario de términos de turismo. https://www.unwto.org/es/ glosario-terminos-turisticos

UNWTO (2021b). COVID-19: Measures to Support Travel and Tourism. https://www.unwto. org/covid-19-measures-to-support-travel-tourism

UNWTO (2021c). Tourism back to 1990 levels as arrivals fall by more than 70\%. https://www. unwto.org/news/tourism-back-to-1990-levels-as-arrivals-fall-by-more-than-70

UNWTO (2021d). 2020: A year in review. https://www.unwto.org/covid-19-and-tourism-2020

UNWTO (2021e). UNWTO Tourism Data Dashboard. https://www.unwto.org/es/ unwto-tourism-dashboard

Weinz, W., Baum, T., Busquets, J., Curran, K., Servoz, L., Spainhower, J., y Myers, J. (2010). Developments and challenges in the hospitality and tourism sector. Geneva: International Labor Organization.

WTTC (2021). COVID-19 Hub. https://wttc.org/COVID-19

Yang, E. C. L., y Nair, V. (2014). Tourism at risk: A review of risk and perceived risk in tourism. Asia-Pacific Journal of Innovation in Hospitality and Tourism, 3(2), 1-21.

Yang, W., Wang, D., y Chen, G. (2011). Reconstruction strategies after the Wenchuan earthquake in Sichuan, China. Tourism Management, 32(4), 949-956.

Zapata, M. J., y Hall, C. M. (2012). Public-private collaboration in the tourism sector: balancing legitimacy and effectiveness in local tourism partnerships. The Spanish case. Journal of Policy Research in Tourism, Leisure and Events, 4(1), 61-83. 